\title{
A Cross-Sectional Study of Midwives' Proactive Behavior in Midwifery Practice
}

\author{
Mestdagh $\mathrm{E}^{1,2 *}$, Timmermans $\mathrm{O}^{2,3}$ and Van \\ Rompaey $\mathrm{B}^{2}$ \\ ${ }^{1}$ Bachelor in Midwifery, Department of Health and Social \\ Work, Artesis Plantijn University College Antwerp, \\ Noorderplaats, Antwerp, Belgium \\ ${ }^{2}$ Centre for Research and Innovation in Care, University \\ Antwerp, Universiteitsplein, Antwerp, Belgium \\ ${ }^{3} \mathrm{HZ}$ University of Applied sciences, Lectorship Healthy \\ region, Edisonweg, NW Vlissingen and The Netherlands \\ *Corresponding author: Mestdagh Eveline, Head of \\ the Midwifery Department, Artesis Plantijn University \\ College Antwerp, Belgium
}

Received: J anuary 11, 2019; Accepted: February 12, 2019; Published: February 19, 2019

\section{Abstract}

Objective: To support midwives in coping with the continuous state of change of midwifery practice by studying proactive behavior in midwifery.

Design: A cross-sectional study investigated associated antecedents of proactive behavior in a group of Belgian and Dutch midwives.

Setting: Midwifery practice in Belgium and the Netherlands.

Participants: Belgian and Dutch midwives ( $n=139)$

Intervention: Midwives answered a questionnaire, from September 2017 until December 2017, regarding six personal, seven individual and three contextual antecedents possibly associated to two types of proactive behavior: proactive idea implementation and voice speaking. A proportional odds logistic regression analyses was executed describing the association between these antecedents and the probability to observe proactive behavior.

Findings: Of all tested prognostic factors, job autonomy, control appraisal and role breadth self-efficacy, referring to the midwives' commitment to perform tasks that go beyond the expectations, were significantly positively associated with proactive behavior.

Conclusions: Midwives having more job autonomy and higher role breadth self-efficacy are positively associated with proactive behavior. Additionally, independent midwives more likely behave proactive. Midwives, more than midwifery students, need a high level of control appraisal in order to show proactive behavior. Midwives tend to lose partly their level of proactive behavior after one working year.

Implications for Practice: In the quest to support midwives in turbulent times, this study uncloses additional insights of proactive behavior in midwifery. Anticipating the various significant antecedents, could strengthen the level of proactive behavior of midwives. The awareness for proactive behavior could positively contribute to the work efficiency and coping attitude of midwives and indirectly contribute to the quality of care for mother and child.

Keywords: Proactive Behavior in Midwifery; Job Autonomy; Role Breadth Self-efficacy; Work Experience; Advanced Practice; Organizational Success; Nursing

\section{Introduction}

Researchers of this study focused on possible tools supporting midwives in the process of continuous changes in midwifery practice. A previous concept analysis by Mestdagh et al. [1] revealed possible benefits of proactive behavior in midwifery. Midwives behaving proactively notice changes as an opportunity, are always one step ahead, anticipate future possible barriers, adapt easily, work autonomously and in a constant quest for efficient, effective and qualitative care strongly leaning to the state-of-the-art. Additionally proactive behavior could result in an increased job satisfaction, workefficiency, commitment and higher coping strategies in increasing resistance of stress [2,3]. On top of that, improved team productivity and organizational success may occur $[4,5]$. Proactive behavior is possibly associated to several individual and/or contextual antecedents who were recently tested in a pilot study within a group $(n=98)$ of midwifery students [6]. Two antecedents, being control appraisal and role breadth self-efficacy, were identified as important predictors of proactive behavior. This study aims to confirm and/or supplement recent insights on antecedents of proactive behavior by studying a group $(n=133)$ of midwives and compare their characteristics and their antecedents on proactive behavior with the results of our earlier study with student-midwives as population.

\section{Background}

Health care practice is characterized by rapid evolutions, the need for cost-effective and accessible health care and constantly changing practices $[7,8]$. In recent years, the context of midwifery practice presents a growing complexity, due to rapid evolutions, such as centralization of care, medicalization of childbirth as well as an overflow of new insights, innovations and availability of evidence on interventions $[7,8,9]$. Births also became increasingly complex. 


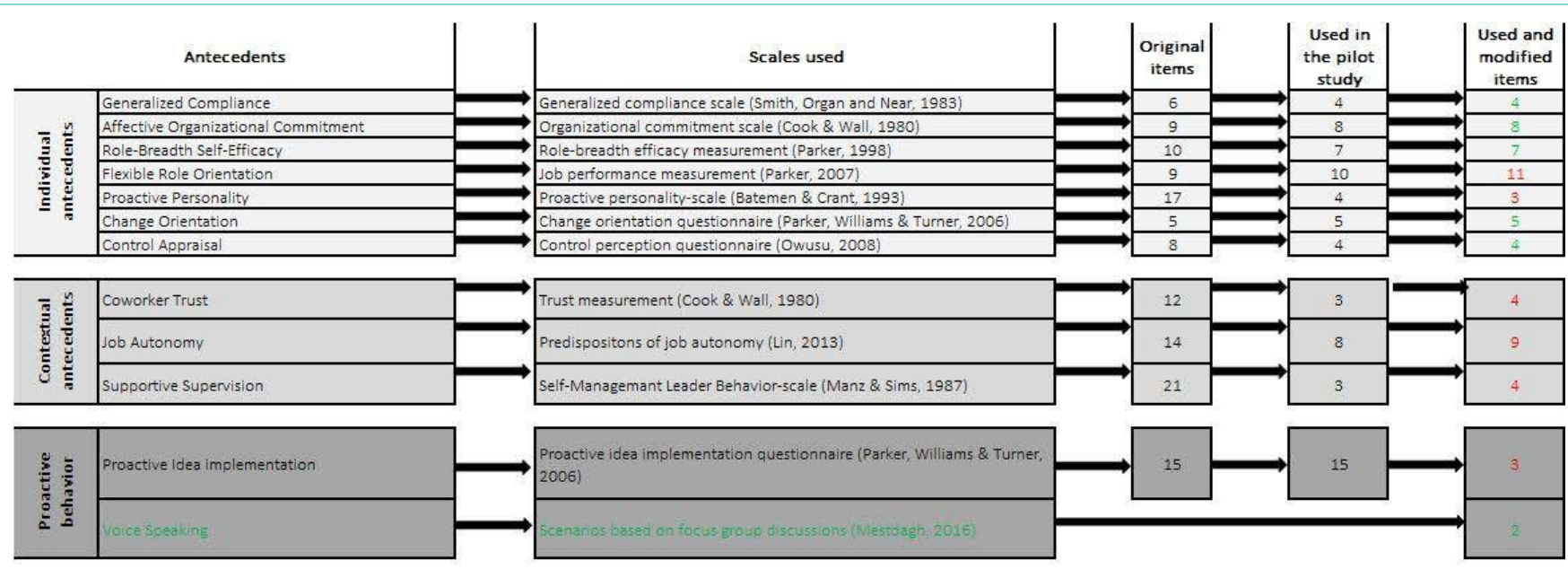

Figure 1: Construction of the questionnaire items.

For example, older women are giving birth, more women that are pregnant are obese and more women are living in very difficult social situations. Midwives are expected to adapt quickly to changes in particular by modifying themselves to keep pace with the continuous changes in their specific working area or in the structures in which they provide care $[10,11]$. Up until now, the qualifications of midwives do not fully meet the needs of labor market and society. Employers report an increasing difficulty in finding staff capable of coping with the developments and innovations. This calls for a new generation of midwives, who proactively move along and possess the characteristics of a reflective practitioner [12]. In the quest for an answer to the developments and innovations in midwifery and midwifery education, health care organizations, universities and governmental institutions mainly focus on operational directly visible matters, e.g. restructuring of protocols, work areas, financing et cetera. Yet, less emphasis is given to underlying, not directly visible aspects of work (processes). We should move the focus of attention to a possible behavioral change, where through the midwife could positively cope and act towards all developments and innovations in midwifery practice. Drawing on the literature proactive behavior of the midwife is identified to support them to cope with the continuous developments in midwifery practice.

This current study explored the association of proactive behavior to several individual and contextual antecedents within a population of midwives. The midwives' informed beliefs and motivation that the behavior will bring about a set of salient outcomes, is an important prerequisite of midwives' attitude towards proactive behavior [13]. Therefore, a supplementary aim of this study is to make midwives more aware of the concept of proactive behavior and its global contribution to the women and infants quality of care $[14,15]$.

\section{Materials and Methods}

\section{Study design}

A recent pilot study of Mestdagh et al. [6] validated a questionnaire to assess proactive behavior in midwifery students. The 75 original predefined questions, adapted to the midwiferyworking context, were translated and retranslated. An expert panel, consisting of lecturers $(n=5)$, researchers $(n=2)$ and midwives (
$=4$ ), determined the content validity on the item level (I-CVI, 0.901.00) as and well the scale-level (S-CVI, 0.89-1.00) [16]. Based on the results of the previous pilot study and the content validity check a 70-item questionnaire with a set of seven individual and three contextual antecedents related to proactive behavior was developed. The questionnaire is subdivided in four categories. The first part consists of a set of six personal and demographical questions. The second category consists of seven individual antecedents: (1) generalized compliance, (2) affective organizational commitment, (3) proactive personality, (4) change orientation, (5) control appraisal, (6) role breadth self-efficacy and (7) flexible role orientation. Third, three contextual antecedents: (1) job autonomy, (2) confidence in the possibilities of fellow students and (3) supportive supervision. Finally, two concepts, proactive idea implementation and voice speaking assessed the level of proactive behavior. The first concept; proactive idea implementation; included five components: 1) time savings, 2) working together more efficiently, 3) achieving improved results, 4) improving quality and/or 5) creating cost. The midwives in this sample were asked if and how many new ideas they had concerning these components, whether they had shared their idea(s) with anyone (their colleagues, their direct manager or others) and whether these ideas were implemented by anyone (themselves or others). The second concept of proactive behavior was voice speaking. This concept was investigated by means of two questions. In a first question, the midwife was asked to indicate if any adjustments were implemented within her working environment in response to shorten possible hospital stays after delivery. The proposed adjustments, e.g. the doubling of the starting dose of an Oxytocin-infusion in case of a labor-induction, were extracted of two earlier focus groups, performed in December 2016 by one of the researchers of this study, with a population of midwives $(n=7$ and $n=6)$. The midwives were then asked to describe their working method whenever one of those adjustments happened. The second question gave some recent working methods based on evidence-based guidelines in midwifery, e.g. the midwifery led care-principles. The midwife was asked to indicate the implemented methods in her working environment. Thereafter the midwives again had to describe their working method in order to implement or preserve these evidence based methods. In both cases, the possible answers fluctuated from reactive to proactive, 
Table 1: Midwives' personal characteristics.

\begin{tabular}{|c|c|c|c|}
\hline \multicolumn{2}{|c|}{ Personal characteristics } & $\mathbf{n}$ & $\%$ \\
\hline \multirow{10}{*}{ Age } & $21-25$ & 42 & 30,2 \\
\hline & $26-30$ & 38 & 27,3 \\
\hline & 31-35 & 18 & 12,9 \\
\hline & $36-40$ & 6 & 4,3 \\
\hline & $41-45$ & 7 & 5,0 \\
\hline & $46-50$ & 13 & 9,4 \\
\hline & $51-55$ & 5 & 3,6 \\
\hline & $56-60$ & 3 & 2,2 \\
\hline & $>60$ & 2 & 1,4 \\
\hline & Unknown & 5 & 3,6 \\
\hline \multirow{2}{*}{ Nationality } & Belgian & 72 & 52 \\
\hline & Dutch & 67 & 48 \\
\hline \multirow{2}{*}{ Gender } & Female & 137 & 99 \\
\hline & Male & 2 & 1 \\
\hline \multirow{3}{*}{ Education } & Flemish Univeristy College & 113 & 81 \\
\hline & Dutch University College & 22 & 16 \\
\hline & Unknown & 4 & 3 \\
\hline \multirow{5}{*}{ Employment status } & Independent self-employed midwife & 45 & 32 \\
\hline & Midwife in hospital & 76 & 55 \\
\hline & $\begin{array}{l}\text { Combination midwife in hospital and } \\
\text { self-employed }\end{array}$ & 8 & 6 \\
\hline & Nurse & 5 & 4 \\
\hline & Extramural & 5 & 4 \\
\hline \multirow{5}{*}{$\begin{array}{c}\text { Number of years in work } \\
\text { environment }\end{array}$} & $<1$ year & 39 & 28 \\
\hline & 1-5 year & 49 & 35 \\
\hline & 6-10 year & 16 & 12 \\
\hline & $>10$ year & 33 & 24 \\
\hline & Unknown & 2 & 1 \\
\hline
\end{tabular}

based on the defined attributes of proactive behavior in midwifery by Mestdagh et al. [1].

The full development of this questionnaire is elaborated in the study of Mestdagh et al. [6], in summary; an overview is given in Figure 1.

\section{Study participants}

The midwives' characteristics are shown in Table 1. A total of 139 , most female midwives (99\%) and a mean age of 32 year, participated in this study. An approximately equal percentage of Dutch (48\%) compared to Belgian midwives (52\%) was present. More than $81 \%$ of the studied population had obtained their midwifery degree in a Flemish university college compared to $19 \%$ in the Netherlands or others. The working context is subdivided in midwives working in a hospital (55\%), independent self-employed midwives (32\%), a combination of both (6\%) and others (8\%). More than half $(63 \%)$ of the participants had less than 6 years of working experience.

\section{Ethical considerations}

Both the ethical advisory board of social and human sciences at
Table 2: Descriptive statistics for each prognostic factor.

\begin{tabular}{|l|c|c|c|c|c|}
\hline \multicolumn{1}{|c|}{ Variable } & $\mathbf{n}$ & mean & sd & median & Range \\
\hline Age & 134 & 32.24 & 10.49 & 28 & $21-63$ \\
\hline Gender & 139 & 1.01 & 0.12 & 1 & $1-2$ \\
\hline Nationality & 139 & 1.48 & 0.5 & 1 & $1-2$ \\
\hline Employment status & 139 & 1.91 & 0.92 & 2 & $1-5$ \\
\hline Work duration & 139 & 2.34 & 1.14 & 2 & $1-4$ \\
\hline Generalized Compliance & 139 & 16.44 & 2.28 & 17 & $7-20$ \\
\hline Affective Organizational & 139 & 20.65 & 4.23 & 21 & $10-28$ \\
\hline Rommitment & 139 & 25.5 & 5.24 & 26 & $10-35$ \\
\hline Sule-Breadth Self-Efficacy & 139 & 14.26 & 3.35 & 15 & $4-20$ \\
\hline Proactive Personality & 139 & 11.19 & 1.91 & 11 & $6-15$ \\
\hline Change Orientation & 139 & -4.22 & 2.16 & -4 & $-12-1$ \\
\hline Control Appraisal & 139 & 9.88 & 2.36 & 10 & $6-20$ \\
\hline Coworker Trust & 139 & 16.68 & 2.27 & 17 & $8-20$ \\
\hline Job Autonomy & 139 & 28.29 & 5.45 & 27 & $12-40$ \\
\hline Flexible Role Orientation & 139 & 32.37 & 2.98 & 33 & $11-44$ \\
\hline Voice speaking & 139 & 2.46 & 2 & 2 & $0-8$ \\
\hline Proactive Idea implementation & 139 & 1.46 & 1.79 & 0 & $0-5$ \\
\hline
\end{tabular}

the University of Antwerp, Belgium (SHW_17_31_02 ) as well as the commission of medical ethics of the GZA hospitals in Antwerp, Belgium (HD/ef/2017/11.23) gave their ethical approval. An informed consent form, with information on the design and aim of the study was provided to the respondents. All participating midwives, were referred to the confidential aspect of their participation, gave written consent and entrusted that they would never be recognizable in any reports or published work.

\section{Data collection and analysis}

This cross-sectional study wanted to explore possible associations between identifiable antecedents and proactive behavior in midwifery. As a part of their bachelor thesis at the Artesis Plantijn University College in Antwerp, Belgium, all last year midwifery students $(n=54)$, had to motivate at least two midwives on their clinical placements in the period from the $18^{\text {th }}$ of September 2017 until the $15^{\text {th }}$ of December 2017 to participate in this study.

The focus and design of the study was explained by means of an information sheet and an informed consent, signed by all participants. Midwives received the link to the online questionnaire and could reach their student, or one of the researchers at all time in case of ambiguity. This resulted in a very fast feedback principle as part of the content validity check of this questionnaire. For example, one of the first midwives responded that three questions contained a double negation. They were immediately re-formulated so no further ambiguity would occur. The average questionnaire duration was 20 minutes. For general comments, a blank space was left. The research team processed all questionnaires anonymously.

The educational background was primarily checked with all possible University Colleges in the Netherlands and Flanders, but due to some small groups in some University Colleges, three container categories remained as being educated in Flanders, the Netherlands 
Table 3: Proportional odds logistic regression model: factors associated with Proactive Idea Implementation (based on 133 complete cases)

\begin{tabular}{|c|c|c|c|c|}
\hline \multicolumn{5}{|c|}{ Proportional odds logistic regression model } \\
\hline Parameter & Estimate & $95 \% \mathrm{Cl}$ & Estimate* $^{*}$ & $95 \% \mathrm{Cl}^{*}$ \\
\hline Intercept Logit(PII=0) & 1.549 & {$[0.636 ; 2.462]$} & $82.50 \%$ & {$[65.4 \% ; 92.1 \%]$} \\
\hline Intercept Logit(PII $\leq 1)$ & 1.929 & {$[0.996 ; 2.862]$} & $87.30 \%$ & {$[73.0 \% ; 94.6 \%]$} \\
\hline Intercept Logit(PII $\leq 2)$ & 2.75 & {$[1.758 ; 3.742]$} & $93.90 \%$ & {$[85.3 \% ; 97.7 \%]$} \\
\hline Intercept Logit(PII $\leq 3)$ & 3.803 & {$[2.706 ; 4.900]$} & $97.80 \%$ & {$[93.7 \% ; 99.2 \%]$} \\
\hline Intercept Logit(PII $\leq 4)$ & 4.135 & {$[2.993 ; 5.276]$} & $98.40 \%$ & {$[95.2 \% ; 99.5 \%]$} \\
\hline RBSE (continuous, centered around 18) & -0.213 & {$[-0.308 ;-0.118]$} & $0.808^{\star *}$ & {$[0.735 ; 0.889]^{\star *}$} \\
\hline JA (continuous, centered around 17.5) & -0.166 & {$[-0.247 ;-0.086]$} & $0.847^{\star *}$ & {$[0.781 ; 0.917]^{\star \star}$} \\
\hline Work duration (continuous, centered around 1) & 0.386 & {$[0.043 ; 0.729]$} & $1.471^{\star \star}$ & {$[1.044 ; 2.073]^{\star \star}$} \\
\hline Employment status (independent or extramural) & 2.231 & {$[1.328 ; 3.134]$} & $9.309 * *$ & {$[3.773 ; 22.96]^{\star *}$} \\
\hline
\end{tabular}

Cl: Confidence Interval; PII: Proactive Idea Implementation; RBSE: Role Breadth Self-efficacy; JA: Job Autonomy.

${ }^{*}$ Estimate and $\mathrm{Cl}$ on probability scale, back-transformed using inverse logit transformation.

${ }^{*}$ Estimate and $\mathrm{Cl}$ expressed as odds-ratios, back-transformed using the exponential transformation.

The odds ratio for, e.g. a 2-units increase in RBSE can be calculated according to $\mathrm{e}^{(-0.213 \times \triangle R B S E)}$ with $\triangle$ RBSE giving the unit deviation from the median RBSE value of 18 .

or unknown. The working title categories where midwives worked in several possible extramural settings were bundled into one extramural group.

Proportional odds logistic regression was used to describe the distribution of both proactive behaviors, idea implementation and voice speaking, in this study population As not only the categorical nature, but also the ordinal relationship between the categories of both proactive behaviors was taken into account, proportional odds models were necessary [17]. A linear combination of parameters define the different cumulative loge odds (i.e. logits) because these models were parameterized. Five cumulative logits were defined for proactive idea implementation, which has six possible outcome values. An example is given in Equation 1 of the model for the logit of the cumulative probability of observing a PII score $\leq 1$. For voice speaking, which has eight possible outcome values, eight cumulative logits were defined [17].

$$
\operatorname{Logit}(\operatorname{Pr}[P I I \leq 1])=\log _{e}\left(\frac{\operatorname{Pr}[P I I \leq 1]}{1-\operatorname{Pr}[P I I \leq 1]}\right)=\beta_{0}+\beta_{1} \times \operatorname{Cov}_{1}+\beta_{2} \times \operatorname{Cov}_{2}+\ldots
$$

Equation 1

The cumulative logit is defined by an intercept term $\left(\beta_{0}\right)$ and additional parameters $\left(\beta_{1}, \beta_{1}\right.$, etc. $)$ describing the change in the cumulative logit as a function of the individual and contextual antecedents as well as the personal characteristics of the midwives, hereinafter referred to as the specific prognostic factors $\left(\operatorname{Cov}_{1}, \operatorname{Cov}_{2}\right.$, etc.). Afterwards, using the inverse logit transformation, logits are back-transformed to cumulative probabilities By subtraction from the cumulative probabilities with the probability to observe a proactive idea implementation score less than or equal to 5 being 1 or a voice speaking score less than or equal to 8 being 1 , the probabilities for each category were obtained.

The association with the probabilities of observing proactive idea implementation and/or voice speaking outcomes were explored by introduction of sixteen different prognostic factors into these models. For comparison purposes continuous prognostic factors, such as supportive supervision, 'flexible role orientation, etc. were centered on the median value used in our previous study [6]. "Forward inclusion" was used guided by Likelihood Ratio Testing (LRT) at the 5\% level of significance. Starting from a model, which contained no prognostic factors, the final model was derived by including all significant factors according to the LRT in a step-wise fashion. Due to the sparseness of the data and the number of categorical prognostic factors considered, only marginal effects of prognostic factors were considered for inclusion in the model, i.e. (2-way) interaction terms were not evaluated. The linearity assumption for the continuous covariates in the final model was assessed after establishment of the appropriate factors in the model. The Hosmer-Lemeshow test was used to demonstrate adequate goodness-of-fit for the final model. Whenever a summed-score was missing, the midwife was deleted from the study. In this way only 134 complete-cases remained. Model fitting to the observed data, and thereafter, evaluation of the goodness-of-fit of the model as well as the uncertainty of the estimated parameters was performed in $\mathrm{R}^{\oplus}$ ( $\mathrm{R}$ foundation for statistical computing, Vienna, Austria).

\section{Results}

Table 3 shows the estimated parameters for proactive idea implementation from the final proportional odds logistic regression model. Only role breadth self-efficacy, job autonomy, work duration and employment status were significant of all tested prognostic factors, as well as their parameters estimable with acceptable precision (i.e. 95\% confidence intervals not containing zero). Table 3 shows that a Belgian or Dutch midwife, with a role-breadth self-efficacy score of 18, a job autonomy score of 17.5, and work duration score of 1 , has $82.5 \%, 4.8 \%, 6.6 \%, 3.9 \%, 0.6 \%$ and $1.6 \%$ chance of displaying a proactive idea implementation score of $0,1,2,3,4$ or 5 respectively.

Role breadth self-efficacy and job autonomy, negatively associated with the cumulative logits, lead to a shift in the probabilities towards higher proactive idea implementation scores. In contrary, work duration and employment status are associated with increasing probabilities for lower proactive idea implementation scores because of their positive association with the cumulative logits. More quantitatively, for example, table 3 shows that the odds of a proactive idea implementation less than or equal to one for midwives who are in their first working year is 1.471 times the odds of a proactive idea implementation less than or equal to 1 for midwives who are already 
Table 4: Proportional odds logistic regression model: factors associated with Voice Speaking (based on 133 complete cases).

\begin{tabular}{|c|c|c|c|c|}
\hline \multicolumn{5}{|c|}{ Proportional odds logistic regression model } \\
\hline Parameter & Estimate & $95 \% \mathrm{Cl}$ & Estimate* & $95 \% \mathrm{Cl}^{*}$ \\
\hline Intercept Logit(VS=0) & -3.445 & {$[-5.137 ;-1.754]$} & $3.09 \%$ & {$[0.58 \% ; 14.7 \%]$} \\
\hline Intercept Logit(VS $\leq 1)$ & -3.15 & {$[-4.825 ;-1.474]$} & $4.11 \%$ & {$[0.79 \% ; 18.6 \%]$} \\
\hline Intercept Logit(VS $\leq 2)$ & -1.884 & {$[-3.505 ;-0.263]$} & $13.20 \%$ & {$[2.92 \% ; 43.5 \%]$} \\
\hline Intercept Logit(VS $\leq 3)$ & -1.087 & {$[-2.697 ; 0.523]$} & $25.20 \%$ & {$[6.31 \% ; 62.8 \%]$} \\
\hline Intercept Logit(VS $\leq 4)$ & -0.389 & {$[-1.997 ; 1.218]$} & $40.40 \%$ & {$[11.9 \% ; 77.2 \%]$} \\
\hline Intercept Logit(VS $\leq 5)$ & 0.671 & {$[-0.991 ; 2.333]$} & $66.20 \%$ & [27.1\%; 91.1\%] \\
\hline Intercept Logit(VS $\leq 6)$ & 1.1 & {$[-0.623 ; 2.824]$} & $75.00 \%$ & {$[34.9 \% ; 94.4 \%]$} \\
\hline Intercept Logit(VS $\leq 7)$ & 2.223 & {$[-0.162 ; 4.284]$} & $90.20 \%$ & {$[45.9 \% ; 98.6 \%]$} \\
\hline CA (continuous, centered around 9) & -0.197 & {$[-0.346 ;-0.049]$} & $0.821^{\star \star}$ & {$[0.707 ; 0.952]^{\star \star}$} \\
\hline SS (continuous, centered around 6) & 0.114 & {$[0.018 ; 0.209]$} & $1.121^{\star *}$ & {$[1.018 ; 1.232]^{\star *}$} \\
\hline FRO (continuous, centered around 24) & 0.177 & {$[0.025 ; 0.329]$} & $1.194^{* *}$ & {$[1.025 ; 1.389]^{\star *}$} \\
\hline
\end{tabular}

Cl: Confidence Interval; VS: Voice Speaking; CA: Control Appraisal; SS: Supportive Supervision; FRO: Flexible Role Orientation.

*Estimate and $\mathrm{Cl}$ on probability scale, back-transformed using inverse logit transformation.

"Estimate and $\mathrm{Cl}$ expressed as odds-ratios, back-transformed using the exponential transformation.

The odds ratio for, e.g. a 2-units increase in CA can be calculated according to $\mathrm{e}^{(-0.197 \times \triangle \mathrm{CA})}$ with $\triangle \mathrm{CA}$ giving the unit deviation from the median $\mathrm{CA}$ value of 9 .

working for more than one year. In other words, the odds ratio for a proactive idea implementation less than or equal to one for midwives who in their first working year versus midwives who are over the first year is 1.471 (95\% CI: $[1.044 ; 2.073])$, or a $47.1 \%$ increase in the odds. Moreover, the odds of a proactive idea implementation less than or equal to one for midwives who work in a hospital is 9.309 times the odds of a proactive idea implementation less than or equal to 1 for midwives who work independently or extramural. In other words, the odds ratio for a proactive idea implementation less than or equal to one for midwives who work independently or extramural versus midwives who work in a hospital is 9.309 (95\% CI: [3.773; 22.96]), or a $6.91 \%$ increase in the odds.

Due to the assumption underlying the proportional odds logistic regression model, this odds ratio holds for all adjacent outcome values, i.e. the odds for a proactive idea implementation less than or equal to 4 is also elevated by $47.1 \%$ for first year midwives versus longer working midwives. On the same account, table 3 shows that the odds ratio for a unit increase in role breadth self-efficacy or job autonomy is 0.808 (95\% CI: [0.735; 0.889]) and 0.847 (95\% CI: [0.781; $0.917])$, respectively.

The estimated parameters from the final proportional odds logistic regression model for voice speaking are shown in Table 4. Of all tested prognostic factors, control appraisal, supportive supervision and flexible role orientation were significant and their parameters estimable with acceptable precision (i.e. 95\% confidence intervals not containing zero). Table 4 shows that a midwife, with a control appraisal score of 9, a supportive supervision score of 6 and flexible role orientation score of 24 , has $3.09 \%, 1.02 \%, 9.09 \%, 12 \%, 15.2 \%$, $25.8 \%, 8.8 \%, 15.2 \%$ and $9.8 \%$ chance of presenting a voice speaking score of $0,1,2,3,4,5,6,7$ or 8 respectively.

Control appraisal is negatively associated with the cumulative logits and therefore lead to a shift in the probabilities towards higher voice speaking scores. In contrary, supportive supervision and flexible role orientation are positively associated with the cumulative logits and therefore associated with increasing probabilities for lower voice speaking scores.

\section{Discussion}

This study explored possible associations of individual and contextual antecedents and the likelihood of behaving proactively expressed as proactive idea implementation or voice speaking. On top of that, the researchers wanted to compare the possible associations found with midwifery students [6] and midwives.

A first observation comparing the participant groups in both studies reveals that midwives had significant higher median scores for practically all the antecedents (Table 2) compared with students, but results of association with the antecedents are similar. Different reasons could explain that. At first possibly the midwives could have fulfilled the questionnaire with social desirable answers because they might felt controlled despite complete confidentiality was guaranteed. Secondly, it could mean that there is still another reason whether or not midwives behave proactive which was not included in the questionnaire. To find this out, a current qualitative study of the research team looks for possible other facilitators and barriers of proactive behavior in midwifery. Preliminary results of this study highlight the emphasis on education. There is also a clear need to shift towards a safe and open-discussion culture with all partners in the team the midwife is working in [18]. Midwives link an eligible job autonomy as a stimulator to behave proactively. In addition, the importance of an appreciative leader was mentioned.

Nauta et al. [19] stated that learning and innovative behaviors are seen in people with a high role breadth self-efficacy [19]. It is very reassuring to see this trend in both the midwifery students as well as the midwives with the proactive behavior of idea implementation.

The level of job autonomy did not necessarily came forward with the midwifery students, but was positively associated with proactive idea implementation in this study. However, it is important to remain vigilant to balance the maintenance of heaps of autonomy in to the 
job and good collaboration among midwives based on the needs of women [20].

A complete contrast with the study of the midwifery students is the effect of the individual antecedent: control appraisal. Whereas proactive behavior is seen at midwifery students with a low control appraisal, this study shows that, on the contrary proactive behaving midwives do have a high level of control appraisal. This would mean that midwives value control much more compared to the midwifery students.

Edmondson [21] stated that psychological safety, being the shared belief that safety is guaranteed for interpersonal risk taking, could be a stimulating factor for team learning and/or innovation.

Our findings could not confirm both findings of Bailey et al. [22], stating that proactive behavior is stimulated by supportive supervision. In addition Yin et al. [23] confimred that empowering leadership broadens the scope of the employees and therefore work more efficiently and tend to behave proactive.

Nevertheless Stzayk et al. [24] linked a high affective organizational commitment to proactive behavior, no significant association was found with proactive behavior in this study. Although, both in the pilots' and in this study population most participants had a relative high affective organizational commitment-score.

The limitations of this study are that for two of the antecedents (generalized compliance 0.65 and affective organizational commitment 0.66 ) the internal reliability tests, scored by Cronbach's alpha could get a higher score $(>0.70)$ when one question would be deleted. After studying the concerned questions, it is not sure, if both questions were filled in randomly or if the bundled questions are not consistent. Both questions will be monitored in a larger study as described below. Second, data in this cross-sectional study were collected by self-report questionnaires. Although cognitivemotivational states is quite appropriately measured by self-reports [25], the perception towards proactive behavior might be biased by the situation the midwife is in at the time of data collection. However, gauging midwives' level of proactivity from other sources, such as colleagues or supervisors, has its own disadvantages, including observational bias (e.g., midwives or midwifery students may show more proactive behavior when they are observed) and egocentric bias, by means of impression management (e.g., the management team reporting, "of course, their team members are proactive") [26]. In addition, studying proactive behavior involves questioning and challenging possible accepted practices. This in itself is not always appreciated by the management team or colleagues and can be assessed negatively [27]. Therefore, all this taken into account, selfreport measurements were used.

\section{Conclusion}

The aim of this study was to confirm and/or supplement the impact of individual and/or contextual antecedents on proactive behavior elaborated in the recent study of Mestdagh et al. [6]. According to this study, midwives with a high role breadth selfefficacy and high job autonomy more likely show proactive behavior. In contrast to midwifery students, midwives need a high level of control appraisal having the tendency to show proactive behavior. A higher score on supportive supervision, by means of co-workers and or the management, and flexible role orientation, in where midwives are aware of the accountability of the development of their own role as a midwife, showed a slight increase of proactive behavior. The most frightening, but not entirely unexpected result was that midwives with more than one year of working experience, are les proactive compared to midwives who are in their first working year. As an additional finding midwives who work independently are more likely to show proactive behavior compared to midwives working elsewhere. The results of this study can be used in order to stimulate proactive behavior on the midwifery-working floor as it might contribute to the increase of the quality of maternity care. Future research should focus in which way the role breadth self-efficacy-level of the midwives can be encouraged [28-41], how proactive behavior can be maintained after one year of working experience and how midwives in hospital settings can be motivated to behave as proactive as there self-employed colleagues.

\section{Acknowledgment}

Eveline Mestdagh wishes to thank Dr. Pieter Colin for his contribution in the statistical analysis of this data.

\section{References}

1. Mestdagh E, Van Rompaey B, Beeckman K, Bogaerts A, Timmermans O. A concept analysis of proactive behavior in midwifery. J Adv Nurs. 2016; 72: 1236-1250.

2. Parker SK, Sprigg CA. Minimizing strain and maximizing learning: the role of job demands, job control, and proactive personality. J Appl Psychol. 1999; 84: 925-939.

3. Griffin MA, Neal A, Parker SK. A new model of work role performance: Positive behavior in uncertain and interdependent contexts. Academy of Management Journal. 2007; 50: 327-347.

4. Crant JM. Proactive behavior in organizations. Journal of Management. 2000 26: 435-462.

5. Seibert SE, Kraimer ML, Crant JM. What Do Proactive People Do? A Longitudinal Model Linking Proactive Personality and Career Success. Personnel Psychology. 2001; 54: 845-874.

6. Mestdagh E, Timmermans O, Colin PJ, Van Rompaey B. A cross-sectional pilot study of student's proactive behavior in midwifery education: Validation of a developed questionnaire. Nurse Educ Today. 2018; 62: 22-29.

7. Bauer JC. Nurse practitioners as an underutilized resource for health reform: evidence-based demonstrations of cost-effectiveness. J Am Acad Nurse Pract. 2010; 22: 228-231.

8. Timmermans O, Van Linge R, Van Petegem P, Van Rompaey B, Denekens $\mathrm{J}$. Team learning and innovation in nursing, a review of the literature. Nurse Educ Today. 2012; 32: 65-70.

9. Healy S, Humphreys E, Kennedy C. Midwives and obstetricians' perceptions of risk and its impact on clinical practice and decision-making in labor: An integrative review. Women Birth. 2016; 29: 107-116.

10. Carman JM, Shortell SM, Foster RW, Hughes EF, Boerstler H, JL OB, et al. Keys for successful implementation of total quality management in hospitals. Health Care Manage Rev. 2010; 35: 283-293.

11. Lemieux-Charles L, McGuire WL. What do we know about health care team effectiveness? A review of the literature. Med Care Res Rev. 2006; 63: 263300.

12. Westerlaken A, Brouns M, Drost H, Leerink B, Meyboom-de Jong B, Schouten $M$, et al. Voortrekkers in verandering in zorg en opleidingen-partners innovative. Advies van de verkenningscommissie hbo gezondheidszorg. 2013.

13. Glasman LR, Albarracin D. Forming attitudes that predict future behavior: 
a meta-analysis of the attitude-behavior relation. Psychol Bull. 2006; 132: 778-822.

14. Renfrew MJ, McFadden A, Bastos MH, Campbell J, Channon AA, Cheung $\mathrm{NF}$, et al. Midwifery and quality care: findings from a new evidence-informed framework for maternal and newborn care. Lancet. 2014; 384: 1129-1145.

15. Weaver K, Mitcham C. Nursing concept analysis in North America: state of the art. Nursing Philosophy. 2008; 9: 180-194.

16. Polit DF, Beck CT. Nursing Research: Generating and Assessing Evidence for Nursing Practice (9 ed.). Philadelphia: Williams \& Wilkins. 2012.

17. Agresti A. Categorical Data Analysis: Wiley. 2002.

18. Giebels E, de Reuver RS, Rispens S, Ufkes EG. The Critical Roles of Task Conflict and Job Autonomy in the Relationship between Proactive Personalities and Innovative Employee Behavior. J Appl Behav Sci. 2016 52: 320-341.

19. Nauta A, van Vianen A, van der Heijden B, van Dam K, Willemsen M. Understanding the factors that promote employability orientation the impact of employability culture, career satisfaction, and role breadth self-efficacy. Journal of Occupational and Organizational Psychology. 2009; 82: 233-251.

20. Perdok H, Cronie D, van der Speld C, van Dillen J, de Jonge A, Rijnders M, et al. Experienced job autonomy among maternity care professionals in The Netherlands. Midwifery. 2017; 54: 67-72

21. Edmondson AC. Learning from failure in health care: frequent opportunities, pervasive barriers. Qual Saf Health Care. 2004; 13: ii3-9.

22. Bailey C, Blake C, Schriver M, Cubaka VK, Thomas T, Martin Hilber A. A systematic review of supportive supervision as a strategy to improve primary healthcare services in Sub-Saharan Africa. Int J Gynaecol Obstet. 2016; 132 117-125.

23. Yin K, Xing L, Li C, Guo Y. Are Empowered Employees More Proactive? The Contingency of How They Evaluate Their Leader. Front Psychol. 2017 8: 1802.

24. Stazyk EC, Pandey SK, Wright BE. Understanding Affective Organizationa Commitment: The Importance of Institutional Context. American Review of Public Administration. 2011; 41: 603-624.

25. Mauss IB, Robinson MD. Measures of emotion: A review. Cognition \& emotion. 2009; 23: 209-237.

26. Merkl-Davies DM, Brennan NM. A conceptual framework of impression management: new insights from psychology, sociology and critical perspectives. Accounting and Business Research. 2011; 41: 415-437.

27. Frese M, Fay D. Personal initiative: An active performance concept for work in the $21^{\text {st }}$ century. Research in Organizational Behavior. 2001; 23: 133-187.
28. Axtell CM, Parker SK. Promoting role breadth self-efficacy through involvement, work redesign and training. Human Relations. 2003; 56: 113131.

29. Alexander G. Perceived control and subjective well-being across nations and across the life span. In E. D. a. E. M. Suh (Ed.), Culture and Subjective WellBeing. Massachusetts The Massachusetts Institute of Technology Press. 2000; 319-339.

30. Bateman TS, Crant JM. The proactive component of organizational behavior: A measure and correlates. Journal of organizational behavior. 1993; 14: 103118.

31. Cook J, Wall TD. New work attitude measures of trust, organizational commitment and personal need non-fulfillment. Journal of Occupational Psychology. 1980; 53: 39-52.

32. Council Eu. Conclusions van de Read over de modernisering van het hoger onderwijs. Publicatieblad van de Europese Unie. 2011.

33. Lau DC, Liden RC. Antecedents of coworker trust: leaders' blessings. J App Psychol. 2008; 93: 1130-1138.

34. Lin BYJ, Lin YK, Lin CC, Lin TT. Job autonomy, its predispositions and its relation to work outcomes in community health centers in Taiwan. Health Promotion International. 2013; 28: 166-177.

35. Manz CC, Sims HP. Leading workers to lead themselves: the externa leadership of self-managing work teams. Administrative Science Quarterly. 1987; 32: 106-128.

36. Owusu-Ansah FE. Control Perceptions and Control Appraisal: Relation to Measures of Subjective Well-Being. Ghana Medical Journal. 2008; 42: 61-67.

37. Parker SK. Enhancing role breadth self-efficacy: the roles of job enrichment and other organizational interventions. J Appl Psychol. 1998; 83: 835-852.

38. Parker SK. 'That is my job': How employees' role orientation affects their job performance. Human Relations. 2007; 60: 403-434.

39. Parker SK, Williams HM, Turner N. Modeling the antecedents of proactive behavior at work. J Appl Psychol. 2006; 91: 636-652.

40. Smith CA, Organ, Dennis W, Near Janet P. Organizational citizenship behavior: Its nature and antecedents. Journal of Applied Psychology. 1983; 68: 653-663

41. Yew LT. Understanding the antecedents of affective organizational commitment and turnover intention of academics in Malaysia: The organizational support theory perspectives. African Journal of Business Management. 2011; 5: 2551-2562.
Ann Nurs Res Pract - Volume 4 Issue 1 - 2019

ISSN: 2572-9403 | www.austinpublishinggroup.com

Mestdagh et al. (C) All rights are reserved
Citation: Mestdagh E, Timmermans O and Van Rompaey B. A Cross-Sectional Study of Midwives' Proactive Behavior in Midwifery Practice. Ann Nurs Res Pract. 2019; 4(1): 1031 